\title{
Fiebre de origen desconocido en pediatria: reporte de un caso
}

\author{
Mervin José Moya Peñafiel* \\ Claudia Carolina Pulgarín Gutiérrez**
}

\begin{abstract}
*Médico General. Coordinador Médico, de Farmacovigilancia y de Urgencias. Honorable Miembro de Junta Directiva de la ESE Hospital César Uribe Piedrahita. Caucasia. Antioquia. Colombia.

**Médico General. Coomeva. Manizales. Caldas. Colombia.

Correspondencia: Dr. Mervin José Moya Peñafiel. Dirección: Transversal 29 \# 1 A - 145, Barrio Brisas del Río, Fundación, Magdalena, Colombia. Correo electrónico: mervin102988@outlook.com
\end{abstract}

\section{RESUMEN}

La fiebre de origen desconocido es una entidad infrecuente que se define como la fiebre que persiste por más de tres semanas luego de investigación clínica intensa, con diversidad y complejidad en cuanto a su etiología, abordaje clínico y enfoque terapéutico. Innumerables casos se resuelven lastimosamente sin determinar un diagnóstico definitivo, orientados simplemente por sintomatología y hallazgos paraclínicos incompletos. Por este motivo, en este artículo se presenta el caso clínico de un paciente de 13 años de edad con fiebre intermitente de un mes de evolución a quien se le realizan estudios pertinentes durante cinco semanas de hospitalización para establecer la causa, asignándose el diagnostico de Artritis Juvenil o Enfermedad de Still por determinaciones aisladas como algunos síntomas referidos y el valor de ferritina encontrado sugestivo de la patología. A partir de ello, el objetivo de este artículo es reconocer la dificultad que enmascara el abordaje diagnóstico y terapéutico de la enfermedad, especialmente en la edad pediátrica. MÉD UIS. 2016;29(1):61-9.

Palabras Claves: Fiebre de Origen Desconocido. Ferritina. Reumatología. Artritis Juvenil.

\section{Fever of unknown origin in pediatrics: a case report}

\section{ABSTRACT}

Fever of unknown origin is a rare entity which is defined as fever that persists for more than three weeks of intense clinical research with diversity and complexity in its etiology, clinical approach and therapeutic approach. Countless cases are resolved without determining unfortunately a definitive diagnosis, symptoms and geared just for paraclinical findings incomplete. For this reason, this paper presents a case of a child under 13 years of age with intermittent fever of $39-40^{\circ} \mathrm{C}$ for one month duration who is relevant studies conducted during five weeks of hospitalization to determine the cause, assigning the diagnosis of Still's disease by single determinations as some symptoms reported and ferritin value suggestive of pathology found. From this, the aim of this paper is to recognize the difficulty masking the diagnosis and therapeutic management of the disease, especially in children. MÉD UIS. 2016;29(1):61-9.

Keywords: Fever of Unknown Origin. Ferritins. Rheumatology. Arthritis Juvenile.

¿Cómo citar este artículo?: Moya MJ, Pulgarín CC. Fiebre de origen desconocido en pediatría: reporte de un caso MÉD.UIS. 2016;29(1):61-9.

\section{INTRODUCCIÓN}

La fiebre en general es un motivo de consulta muy frecuente en los centros de salud y en hospitales a nivel mundial convirtiéndose en una entidad de gran valor investigativo por el impacto y complejidad que tiene para la ciencia médica'. Además, es uno de los signos más frecuentes en la práctica pediátrica, de fácil abordaje en la mayoría de los $\operatorname{casos}^{2}$. Sin embargo, la Fiebre de Origen Desconocido (FOD), variante de la fiebre general, es un ente relativamente infrecuente y puede ser la manifestación de una gran 
variedad de patologías 3 . Si bien no es una entidad clínica habitual, constituye actualmente un desafío diagnóstico y una causa importante de ansiedad para padres y médicos tratantes, frente a lo cual existen escasos reportes en la literatura científica y falta de consenso para su manejo ${ }^{4}$.

Según lo reportado por la literatura, la principal causa de FOD en niños en países en desarrollo son las infecciones, por tanto, en la evaluación inicial se deben tomar pruebas de laboratorio para determinar si existen infecciones bacterianas graves. Las colangiopatías y las neoplasias son temas de importancia en la FOD, en este caso el uso de técnicas de exploración como el TAC y la ecografía permiten establecer un diagnóstico como por ejemplo los tumores ocultos. Teniendo en cuenta la complejidad de la patología, el enfoque terapéutico se basa en la etiología encontrada, aunque en ciertos casos es necesario el manejo empírico con antibioticoterapia, corticoides, analgésicos, entre otros.

Es importante resaltar la diferencia entre la FOD con la Enfermedad de Still (ES). La primera hace referencia a la fiebre que persiste durante varias semanas ante el inicio de manejo medico empírico asociado a búsqueda etiológica por medio de la utilización de exámenes de laboratorio y de imágenes diagnósticas sin respuesta diagnóstica concisa, mientras que la segunda es una patología diagnosticada por medio de sintomatología asociado a resultados de paraclínicos alterados como el valor de la ferritina en sangre, hallándose aumentado en esta.

En ciertos casos, la resolución completa de la FOD es tan compleja que no se logra determinar el agente o el evento desencadenante, existiendo una cantidad relevante de patologías que enmascaran esta problemática diagnóstica. Entre muchos, se puede citar la ES, que se define como un proceso inflamatorio multisistémico de causa desconocida caracterizada por episodios diarios de fiebre, rash cutáneo, artralgia, artritis y mialgia. En menores de 15 años, el término está en desuso y se prefiere utilizar artritis juvenil idiopática 5 .

En este artículo se realiza un estudio observacional descriptivo como presentación de caso clínico a través de la revisión detallada de la historia clínica de un paciente de 13 años de edad que consta de cuadro sindrómico, abordaje inicial, modalidad diagnóstica, tratamiento, pronóstico y progreso de la enfermedad. Así mismo, se realiza una revisión de literatura médica científica con la actualización correspondiente en cuanto a esta temática por medio de artículos y textos pediátricos recientes de revistas médicas internacionales y de algunos documentos de medicina y de guías de manejo de diferentes bases de datos científicas de la web.

El objetivo de este artículo es confirmar que existen algunos casos de FOD en donde se presenta incapacidad para determinar la causa o el origen de los mismos, especialmente cuando se agotan los estudios paraclínicos y cuando la sintomatología no aporta mayor información. Además, se realiza una descripción de la temática tratada y un análisis profundo del adecuado abordaje diagnóstico y terapéutico de la enfermedad.

\section{Presentación del Caso}

Para la presentación de siguiente caso clínico se utilizó el expediente médico del paciente, los resultados de laboratorios y de imágenes diagnósticas realizadas y las versiones de algunos especialistas en el área de la pediatría involucrados en el tema.

Se trata de un paciente masculino de 13 años de edad, procedente de área rural, con un cuadro clínico de un mes de evolución consistente en fiebre cuantificada en 38,5 a $40^{\circ} \mathrm{C}$, intermitente, presentándose cada día por medio, que no resolvía ante la administración de acetaminofén, quien ocho días antes de la consulta presentó tos húmeda con expectoración que conducía al vómito. Niega la presencia de noxa de contagio y otros síntomas asociados. Refieren no haber realizado viajes en los últimos 15 días a áreas rurales. Niega antecedentes médicos de importancia clínica. El carné de vacunación se encuentra completo para la edad.

Presentaba regular estado general, deshidratado, asténico, adinámico, taquicárdico, febril al tacto, pálido, con mucosas secas, hipotrofia muscular generalizada, exantema maculopapular generalizado, y ligero edema en rodillas, manos y pies. Dentro de los paraclínicos del primer nivel se encuentra leucocitosis importante, anemia microcítica hipocrómica moderada, trombocitosis, PCR elevada y Virus Sincitial Respiratorio (VSR) positivo (Ver Tabla 1). 
Tabla 1: Criterios de Petersdoft y Beeson, 1960 y de Durack y Street, 1991.

\begin{tabular}{|c|c|}
\hline Criterios de Petersdoft y Beeson, 1960 & Criterios de Durack y Street, 1991 \\
\hline $\begin{array}{l}\text { Temperatura mayor a } 38,3^{\circ} \mathrm{C} \text { medida en } \\
\text { varias ocasiones }\end{array}$ & $\begin{array}{l}\text { Clásica: Temperatura mayor a } 38,3^{\circ} \mathrm{C} \text {, de duración mayor a tres } \\
\text { semanas sin diagnostico tras } 3 \text { días de ingreso hospitalario o tres } \\
\text { visitas ambulatorias. }\end{array}$ \\
\hline $\begin{array}{l}\text { Duración de la fiebre mayor a tres } \\
\text { semanas }\end{array}$ & $\begin{array}{l}\text { Nosocomial: Temperatura mayor a } 38,3^{\circ} \mathrm{C} \text { en paciente hospitalizado } \\
\text { y recibiendo atención aguda que no presentaba infección ni la } \\
\text { incubaba en el momento de su ingreso. }\end{array}$ \\
\hline \multirow[t]{2}{*}{$\begin{array}{l}\text { Ausencia de diagnóstico tras una semana } \\
\text { de estudio en el paciente hospitalizado }\end{array}$} & $\begin{array}{l}\text { Neutropénica: Temperatura mayor a } 38,3{ }^{\circ} \mathrm{C} \text { en paciente con } \\
\text { recuento de neutrófilos menores de } 500 / \text { microlitros o en el que se } \\
\text { prevé un descenso hasta ese nivel en uno o dos días. }\end{array}$ \\
\hline & $\begin{array}{l}\text { VIH: temperatura mayor a } 38,3^{\circ} \mathrm{C} \text { a lo largo de cuatro semanas en } \\
\text { pacientes ambulatorios o más de tres días en paciente hospitalizado } \\
\text { con VIH. }\end{array}$ \\
\hline
\end{tabular}

Fuente: E. Santos comaliza. Fiebre de origen desconocido. Un reto diagnostico, 2005

Dentro de los hallazgos de los paraclínicos del hospital del segundo nivel se evidencia cardiomegalia sin consolidaciones ni infiltrados al radiografía de tórax, ecografía abdominal total que reporta ligera esplenomegalia, elevación de ferritina, leucocitosis y leve ascenso de lactato deshidrogenasa. Además, se encuentran reportes normales de perfil renal, perfil hepático, tiempos de coagulación, perfil infeccioso e inmunológico (Ver Tabla 2). Se hospitalizó con diagnósticos de Fiebre de Origen Desconocido, síndrome anémico, síndrome constitucional, esplenomegalia y VSR positivo. Se maneja con hidratación endovenosa a base de Solución Salina 0,9\%, antibioticoterapia, transfusión de glóbulos rojos empaquetados, antipiréticos, oxigenoterapia y paraclínicos de control.

Tabla 2: Exámenes de laboratorio extrainstitucionales

\begin{tabular}{|l|}
\hline \multicolumn{1}{|c|}{ Paraclínico e interpretación } \\
\hline Hemograma con leucocitosis de 23000 a expensas \\
de neutrófilos de $75 \%$ \\
Proteína C Reactiva (PCR) elevada en $192 \mathrm{mg} / \mathrm{L}$ \\
Glucometría normal \\
Parcial de Orina normal \\
Albumina disminuida de $2,7 \mathrm{gr} / \mathrm{dL}$ \\
Astos negativos \\
Virus Sincitial Respiratorio positivo \\
\hline
\end{tabular}

Fuente: Paraclínicos del Hospital de primer nivel de atención

Entre las interconsultas solicitadas por pediatría, el servicio de Infectología sugiere completar estudio serológico solicitando de esta manera todo el perfil infeccioso disponible. Reumatología considera la realización de un mielograma para descartar enfermedad neoplásica. Hemato-oncología indica realización de citometría de flujo y mielocultivo, y por su parte Oftalmología descarta uveítis como enfermedad desencadenante del proceso febril.
El manejo antibiótico instaurado inicialmente se modifica a los diez días por Ceftriaxona. Los exámenes de enfermedades infectocontagiosas y autoinmunes resultaron negativos (Ver Tabla 2).

Posteriormente, el paciente presenta descenso de leucocitos de manera progresiva y persistencia de trombocitosis. Dos semanas después se descartó proceso linfoproliferativo por reporte de mielograma negativo para proceso neoplásico. Se encuentra un indicador importante en los resultados de laboratorio dado por el aumento del valor de la ferritina, indicando un posible origen en enfermedad articular. Una semana después, presentó remisión total de los picos febriles y mejoría de su estado general sin otra sintomatología agregada. Se decide dar egreso hospitalario con medicación antipirética y valoración ambulatoria por Reumatología Pediátrica con diagnostico presuntivo de ES. Ante la evolución favorable, se dio de alta tras 14 días de hospitalización, siendo controlado en consulta externa.

\section{Discusión}

A pesar de las múltiples causas de FOD que se presentan en el territorio colombiano, muchos casos quedan sin diagnosticar, muchas veces por falta de recurso humano en el personal de salud especialista o por la falta de equipamiento tecnológico en las instituciones que prestan estos servicios. En zonas tropicales como ésta, la sintomatología de los pacientes es compatible con un tipo específico patológico relacionado con la transmisión de enfermedades transmitidas por vectores; sin embargo, en una importante cantidad casos se desconoce la causa desencadenante de la FOD aun utilizando todos los estudios disponibles. 
El caso clínico presentado en este artículo compromete a un paciente de 13 años de edad que cursa con picos febriles intermitentes, interdiarios, por más de un mes de duración sin otros síntomas asociados que dirijan a un diagnóstico definitivo, siendo este el motivo primordial para la realización de estudios paraclínicos e imagenológicos desde los más simples hasta los más costosos y complejos con los cuales se cuenta para el abordaje de la FOD. La importancia de este caso radica esencialmente en la imposibilidad de generar un diagnóstico definitivo luego de obtener completa negatividad en un sinnúmero de exámenes solicitados durante la hospitalización del paciente, determinando por descarte y con la escasa orientación sintomatológica y paraclínica que reportaba (valor elevado de ferritina de interpretación sugestiva), un diagnóstico de artritis juvenil o ES, que continuaría siendo evaluado ambulatoriamente para observar la evolución ante manejo empírico con ácido acetil salicílico y antiinflamatorios no esteroideos.

La FOD ha tenido diversas definiciones en la literatura médica en las últimas décadas, generando discrepancias entre estudios e investigaciones que buscan determinar el manejo y el abordaje de dicha entidad. Esta puede manifestarse con una duración similar, pero tendrá signos y síntomas concretos que sugieran un diagnostico diferencial definitivo. Los criterios de Petersdorf y Beeson en 1961 para FOD la categorizaron como la temperatura mayor a $38,3^{\circ} \mathrm{C}$ con una duración mínima de tres semanas sin diagnostico claro después de investigación clínica intensa (Ver Tabla 1). Se eligió ese límite de tiempo para eliminar las posibilidades de que el origen de los picos febriles se debieran a una infección viral autolimitada como la rinofaringitis o gastroenteritis para poder iniciar el estudio completo de las enfermedades con evolución más extensa como las enfermedad reumáticas o neoplásicas que puedan explicarlas $^{6,7}$. Se excluye de esta condición a los pacientes con inmunocompromiso previo $^{8}$.

Con este criterio se descartaban causas de hipertermia habitual, tales como la constitución asténica, la debilidad muscular, la anorexia, la inflamación de los nódulos linfáticos, el estreñimiento y el nerviosismo, que en general, no superan esta temperatura. Asimismo, en otras características excluían cuadros febriles de origen vírico cuya duración no suele ser superior a tres semanas y se resuelven espontáneamente sin necesidad de tratamiento. Estas tres indispensables características fueron utilizadas durante más de 30 años, hasta que
Durack y Street propusieron una nueva definición en 1991 teniendo en cuenta los cambios habidos en los últimos años (Ver Tabla 1). Remarcaron con énfasis que en la sociedad existían diferentes grupos de individuos, y por tanto de pacientes con muy distintas características en relación al sexo, antecedentes personales y familiares, costumbres y estilos de vida y de alimentación, y que el abordaje etiológico y terapéutico no podía ni debía ser igual en todos ellos. Se clasificó entonces la FOD en cuatro grupos atendiendo a las características individuales. La FOD clásica tiene en cuenta una temperatura mayor a $38,3^{\circ} \mathrm{C}$, medida en varias ocasiones, de duración mayor a tres semanas, en la que no se llega a ningún diagnóstico tras tres visitas ambulatorias o tres días de ingreso hospitalario. La FOD nosocomial caracterizada por aparición de una temperatura de $38,3^{\circ} \mathrm{C}$ o superior, determinada en varias ocasiones en un paciente hospitalizado que está recibiendo atención diaria y que en el momento de su ingreso no presentaba infección ni estaba incubándola. El requisito mínimo para establecer el diagnóstico es un período de estudio de tres días, con una incubación de cultivos no inferior a dos días. La FOD neutropénica se caracteriza por una temperatura igual o superior a $38,3^{\circ} \mathrm{C}$, determinada en varias ocasiones en un paciente cuyo recuento de neutrófilos es inferior a $500 / \mu l$ o en el que se prevé un descenso hasta ese nivel en un plazo de uno a dos días. Tras tres días de estudio, incluidos al menos dos días de incubación de cultivos, no se llega a un diagnóstico. La FOD asociada al Virus de la Inmunodeficiencia Humana(VIH)tiene en cuenta una temperatura igual o superior a $38,3^{\circ} \mathrm{C}$, determinada en varias ocasiones a lo largo de un período de más de cuatro semanas en pacientes ambulatorios, o de más de tres días en pacientes hospitalizados con infección por el VIH. El diagnóstico se establece cuando con un estudio adecuado de al menos tres días de duración, incluidos al menos dos días de incubación de los cultivos, no se revela la causa9.

El espectro de enfermedades que causan FOD está determinado por la definición utilizada, factores geográficos y cambios a lo largo del tiempo (aparición de nuevos procedimiento diagnósticos y nuevas situaciones clínicas). Tradicionalmente las enfermedades infecciosas eran la causa más frecuente de FOD. Sin embargo, en los últimos años existe una tendencia a que aumenten las enfermedades inflamatorias no infecciosas como causa de FOD y a que el número de casos que quedan sin diagnóstico sea mayor. Nuevas etiologías infecciosas han sido agregadas continuamente a la 
lista de las causas de FOD en los niños. El virus de Epstein Barr, enfermedad de Lyme, la hepatitis y el VIH son ejemplos de nuevas entidades agregadas en los últimos años ${ }^{10}$ (Ver Tabla 3). El 51\% de los casos son de etiología infecciosa y de este grupo el mayor porcentaje son para infecciones bacterianas seguidas de virales, micóticas y parasitarias; $23 \%$ corresponde a pacientes sin diagnostico; $11 \%$ a enfermedades misceláneas; las colangiopatías corresponden a un $9 \%$ de las que se destacan la artritis reumatoide juvenil o ES que corresponde a un $60 \%$ de este grupo, seguidas por el $15 \%$ por lupus eritematoso sistémico y un $6 \%$ a enfermedades neoplásicas en la que se destaca la leucemia con una incidencia de $41 \%{ }^{11,12}$.

Tabla 3: Paraclínicos institucionales del hospital de segundo nivel

\section{Paraclínicos}

- Radiografía de tórax sin consolidaciones, infiltrados ni cardiomegalia

- Gases arteriales con alcalosis metabólica, pH: 7,46 y $\mathrm{HCO}_{3}$ : 24.

- Uroanálisis negativo

- Perfil renal normal

- Extendido de sangre periférica Leucocitos en cantidad aumentada, anisocitosis moderada, micro y macrocitos, poiquilocitosis moderada, dacriocitos y policromatofilia.

- Tiempos de coagulación normales

- Electrolitos normales

- Hemocultivos negativos

- Ecografía Abdominal con reporte de esplenomegalia

- Ecocardiograma normal y sin vegetaciones11. Bk Seriado negativo

- Virus sincitial respiratorio positivo

- Adenovirus negativo

- Complemento: C3, C4 normales

- Deshidrogenasa láctica (LDH) ligeramente aumentada en 390 U/L

- Factor reumatoideo normal

- Función hepática normal

- Serología VDRL no reactiva

- Antígeno de superficie de Hepatitis B negativo

- Citomegalovirus IgM e lgG: positivo para el histórico o lgG

- Coproscópico negativo

- Sangre Oculta en Heces negativo

- Bilirrubinas normales

- Proteínas totales, globulina, relación albumina/globulinas normales

- Reticulocitos normales

- Paratífico A y B, Tifoide H y O, Proteux OX 19, Brucella Abortus y ANAs negativos

- PPD negativo

- TAC de senos paranasales. Con sinusitis crónica

- Brucella Anticuerpos IgM e IgG negativos

- Tripanosoma Cruzi negativo

- Epstein Barr lgG positivo

- Epstein Barr anticuerpo IgM negativo

- Leptospira IgM e IgG negativo

- Chagas IgG negativo

- TAC de abdomen total con esplenomegalia y quiste renal derecho

- Biopsia de Medula Osea con celularidad del 80\%, hematopoyesis de todas las líneas con predominio de la línea granulocítica; relación mieloeritroide 4:1. Megacariocitos normales en morfología y número. Línea eritroide con cambio megaloblástico. Hay ocasionales plasmocitos.

- TAC de tórax hallazgos atribuibles a atelectasia subsegmentaria basal posterior en el lóbulo inferior izquierdo sin evidencia de lesiones consolidativas, sin alteraciones mediastinales.

- ELISA para VIH negativo

- Mielograma negativo

- Hemograma (control dos semanas después) con leucocitos: $4900 \mathrm{cel} / \mathrm{mm}^{3}$, neutrófilos: 24\%, hemoglobina: $10.70 \mathrm{gr} / \mathrm{dl}$, hematocrito: $35.5 \%, \mathrm{VCM}: 80.2 \mathrm{fl}$, plaquetas: $735000 \mathrm{cel} / \mathrm{mm}^{3}$.

- PCR (control dos semanas después) con descenso a 10 mg/dL

- Velocidad de sedimentación globular ligeramente elevada (control dos semanas después)

Fuente: Paraclínicos del Hospital de segundo nivel de atención 
El proceso diagnóstico de la FOD es uno de los problemas más complejos a los que se enfrenta el clínico en su práctica diaria13,14. Para fines diagnósticos, puede agruparse en cuatro categorías, tales como infecciosa, reumática/inflamatoria, neoplásica y trastornos diversos ${ }^{15,16}$. No existe una diferencia notoria de las etiologías de los países desarrollados con los que están en proceso de desarrollo ${ }^{17}$.

Tratándose de FOD, será conveniente siempre tener un algoritmo que ahorre tiempo y conduzca fácilmente al diagnóstico ${ }^{18,19}$. Para tal efecto, debe seguirse un esquema protocolario para su abordaje, iniciando con la solicitud de los exámenes básicos de laboratorios y con una historia clínica que permita esclarecer las principales causas de fiebre esperadas de acuerdo al lugar de procedencia del paciente. Si esta no se logra determinar, se procede a continuar en la búsqueda exhaustiva de la etiología por medio de la solicitud de paraclínicos de mayor complejidad e indagando más a fondo cualquier dato relevante que pueda generar el historial médico del mismo. Cabe resaltar, que, como es el ejemplo de este caso clínico, se puede llegar al agotamiento de todos los recursos de los cuales se dispone en la institución de salud tanto de laboratorio clínico como de imagenología, sin encontrar causa clara de la fiebre o la etiología de la misma (Ver Figura 1).

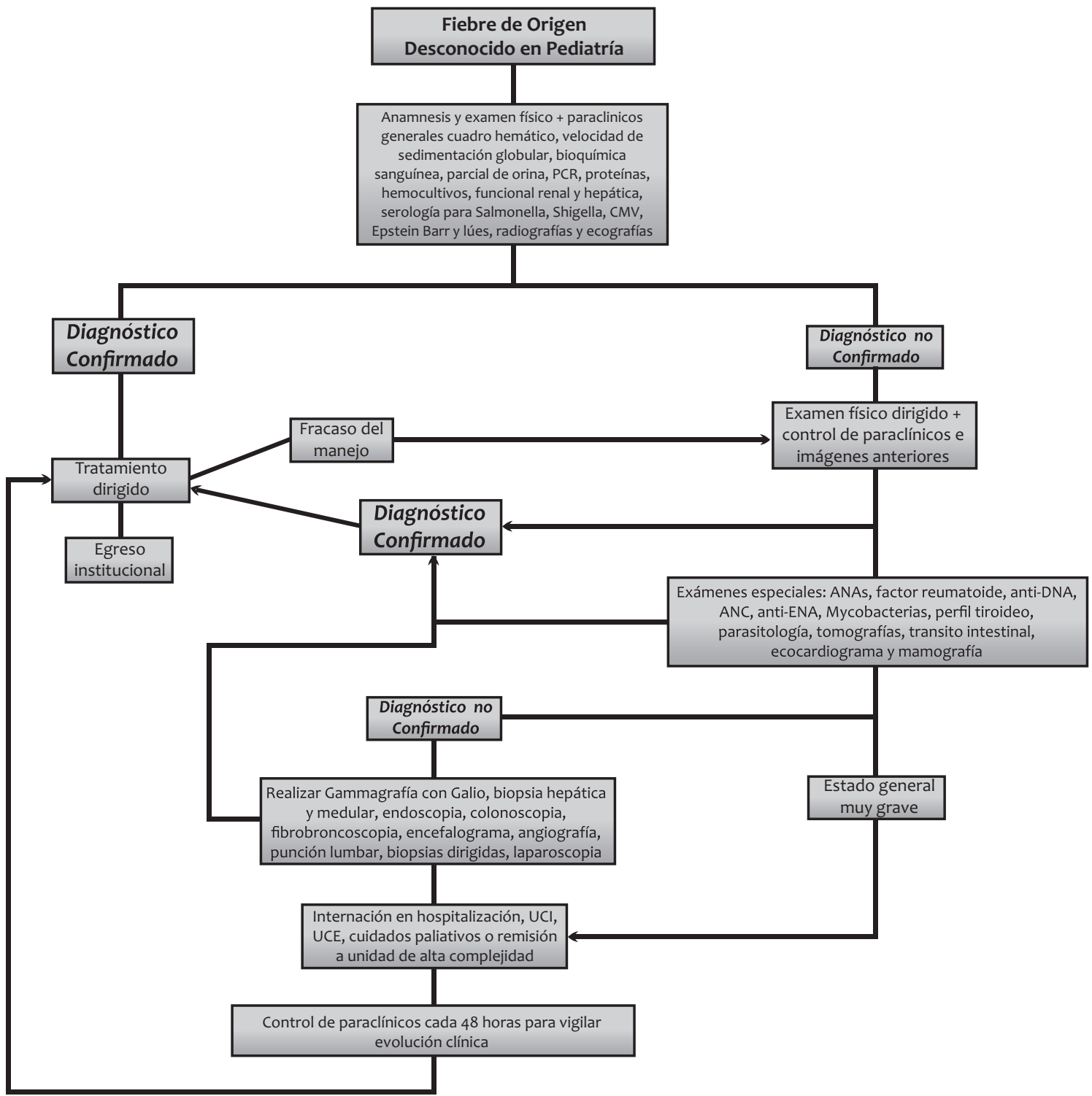

Figura 1: Algoritmo del enfoque de la fiebre de origen desconocido en Pediatría Fuente: Protocolo diagnóstico en fiebre de origen desconocido para países en vías de desarrollo. Romo J, Muñoz J. ISSN 1025 - 5583. 2004;65(2): 127-132 
En el campo terapéutico, a menos que el paciente se encuentre en una enfermedad aguda, la terapia no debe comenzarse hasta que se haya encontrado una causa. Ello se debe a que una terapia no específica rara vez es efectiva y por lo general retarda el diagnóstico. Una excepción se presenta cuando el paciente está neutropénico, por razón de que un retardo en el tratamiento puede conllevar a complicaciones severas. Después de obtener hemocultivos en estos casos, se acostumbra una terapia agresiva con antibióticos de amplio espectro. Los antibióticos se ajustan de acuerdo a los resultados del hemocultivo. Los pacientes infectados con VIH que presenten fiebre e hipoxia, se deben comenzar a tratar con medicamentos en contra de una posible infección por Pneumocystis jiroveci. El tratamiento se ajusta una vez que se ha llegado a un diagnóstico correcto. Se debe evitar tratamientos empíricos para poder continuar el abordaje de los estudios y la observación pertinente de la evolución ${ }^{20}$. Según Cunha ${ }^{21,22}$, existen cuatro situaciones que lo requieren: antibióticos para la endocarditis con cultivo negativo, antiinflamatorios no esteroideos y ácido acetil salicílico para control térmico e inflamatorio, dosis bajas de corticosteroides en sospecha de arteritis de la temporal y naproxeno para la sospecha de fiebre neoplásica. Al encontrar el diagnóstico definitivo, se debe encaminar el manejo a dicha causa ${ }^{23}$.

En el caso clínico reportado, se llevó a cabo anamnesis y examen físico completos, con una observación continua del paciente, se realizaron las pruebas de laboratorio e imagenológicas pertinentes, con lo cual se descartaron etiologías infecciosas, neoplásicas y misceláneas. Se encontraron algunos paraclínicos alterados como la serología para citomegalovirus pudiéndose explicar por contagio vertical o por contacto con líquidos corporales como la saliva, teniendo en cuenta el concepto de que en la etapa de la niñez y la adolescencia es muy fácil la transmisión de esta manera. También se evidenció virus de Epstein Barr positivo pudiendo tener génesis en el mismo evento de transmisión del citomegalovirus, con exposición a la saliva de alguien infectado. Seguidamente, resalta el hallazgo positivo del VSR, recordando que una semana previa el paciente había presentado sintomatología respiratoria que pudiera explicar el descubrimiento.

Tabla 4. Causas de Fiebre de Origen Desconocido.

\begin{tabular}{|l|l|l|l|}
\hline \multicolumn{1}{|c|}{ CATEGORIAS } & \multicolumn{1}{|c|}{ MUY FRECUENTES } & \multicolumn{1}{c|}{ FRECUENTES } & \multicolumn{1}{c|}{ POCO FRECUENTES } \\
\hline $\begin{array}{l}\text { ENFERMEDADES } \\
\text { INFECCIOSAS }\end{array}$ & $\begin{array}{l}\text { Endocarditis bacteriana } \\
\text { subaguda, absceso } \\
\text { intraabdominal, } \\
\text { absceso pélvico, fiebre } \\
\text { tifoidea, tuberculosis } \\
\text { miliar y renal, } \\
\text { meningitis tuberculosa }\end{array}$ & $\begin{array}{l}\text { Epstein Barr virus, } \\
\text { mononucleosis, } \\
\text { citomegalovirus, } \\
\text { enfermedad por arañazo } \\
\text { de gato. }\end{array}$ & $\begin{array}{l}\text { Toxoplasmosis, } \\
\text { brucelosis, leptospirosis, } \\
\text { histoplasmosis, triquinosis, } \\
\text { fiebre por mordedura } \\
\text { de rata, linfogranuloma } \\
\text { venéreo, sinusitis crónica, } \\
\text { enfermedad de Whipple }\end{array}$ \\
\hline $\begin{array}{l}\text { ENFERMEDADES } \\
\text { INFECCIOSAS/REUMATICAS }\end{array}$ & $\begin{array}{l}\text { Enfermedad de Still, } \\
\text { polimialgia reumática }\end{array}$ & $\begin{array}{l}\text { Artritis reumatoide } \\
\text { de inicio tardío, lupus } \\
\text { eritematoso sistémico, } \\
\text { poliarteritis nodosa }\end{array}$ & $\begin{array}{l}\text { Arteritis de Takayasu, } \\
\text { enfermedad de Kikuchi, } \\
\text { gota poliarticular, } \\
\text { seudogota familiar, fiebre } \\
\text { mediterránea, sarcoidosis }\end{array}$ \\
\hline $\begin{array}{l}\text { ENFERMEDADES } \\
\text { NEOPLASICAS }\end{array}$ & Linfomas & $\begin{array}{l}\text { Enfermedades } \\
\text { mieloproliferativas, } \\
\text { carcinoma de colon }\end{array}$ & $\begin{array}{l}\text { Mixomas articulares, } \\
\text { tumores del sistema } \\
\text { nervioso central }\end{array}$ \\
\hline $\begin{array}{l}\text { ENFERMEDADES } \\
\text { MISCELANEAS }\end{array}$ & $\begin{array}{l}\text { Fiebre por drogas, } \\
\text { cirrosis alcohólicas }\end{array}$ & $\begin{array}{l}\text { Enfermedad de Crohn } \\
\text { facticia }\end{array}$ \\
\hline
\end{tabular}

Fuente: Fever of Unknown Origin: clinical overview of classic and current concepts burke A. Chuna, MD, MACP infect dis clin N Am 21 (2007), pag 880 .

Cabe resaltar, que el estudio del síndrome febril de origen desconocido de este paciente se extiende en un transcurso de varias semanas debido a la persistencia de sintomatología a pesar del tratamiento empírico de las posibles causas de focos febriles antes mencionados, sin respuesta favorable.
Con relación a la disminución del valor de la PCR y los glóbulos blancos, se debe tener en cuenta que es lo esperado dentro del contexto clínico de la evolución de la ES, posterior al manejo con antiinflamatorios no esteroideos y acetaminofén, así como la terapia antibiótica para el proceso pulmonar que presentaba 
el paciente. Luego del enfoque terapéutico, el varón mejoró progresivamente por lo cual se genera egreso institucional con seguimientos ambulatorios por el servicio de reumatología con diagnóstico presuntivo de ES, teniendo en cuenta que a un $23 \%$ de los pacientes no se les encuentra la causa desencadenante. Los únicos criterios que orientaron a este dictamen médico durante la etapa de hospitalización fueron la fiebre intermitente prolongada, el edema en extremidades superiores e inferiores, y el valor elevado de la ferritina a $1487,9 \mathrm{ng} / \mathrm{ml}$, siendo el valor normal en niños de 18 a $300 \mathrm{ng} / \mathrm{ml}^{24}$.

La ES corresponde a un desorden inflamatorio sistémico, de etiología desconocida, caracterizado por fiebre en aguja, dolor faríngeo, compromiso articular, rash maculopapular evanescente, linfadenopatías, hepatoesplenomegalia y leucocitosis. En su enfoque y diagnóstico clínico se han referenciado una gran variedad de estudios que reportan la determinación de altos valores de ferritina sérica como marcador diagnóstico, de actividad y monitorización de efectividad del tratamiento. Se han sugerido varios niveles diagnósticos de ferritina sérica en los distintos estudios realizados, entre ellos niveles de ferritina mayor o igual a $1000 \mathrm{ng} / \mathrm{ml}$ asociados a clínica característica son sugerentes de ES, detección de valores mayores a $3000 \mathrm{ng} / \mathrm{ml}$ debiera orientar a ES en enfermedad febril aguda cuando se han descartado infecciones virales y bacterianas.

Sin embargo, este estudio sólo considera un escaso número de pacientes con altos niveles de ferritina (mayor o igual a $4000 \mathrm{ng} / \mathrm{ml}$ ) que son encontrados en pacientes con ES activa. En un estudio reciente, Fautrel y cols observaron que niveles de ferritina glicosilada menores a $20 \%$ y niveles elevados de ferritina son marcadores de ES. Una ferritina mayor a cinco veces el valor normal es de valor diagnóstico, pero con una sensibilidad baja en este estudio probablemente porque fueron incluidos pacientes con enfermedad inactiva. Aún cuando han sido reportados altos niveles de ferritina en otras condiciones, rara vez exceden de $3000 \mathrm{~m} / \mathrm{I}^{25,26}$.

El reporte de casos clínicos con características similares al expuesto en este artículo en la literatura científica es muy bajo, siendo una barrera importante para elaborar conceptos comparativos entre sí. Cabe resaltar que en el año 2006 en una publicación de una revista boliviana se presentó el caso clínico de un varón de ocho años de edad quien presento la misma orientación clínica que la del paciente de este caso, siendo importante destacar que aquel presentó diferencias en la aparición de los síntomas, iniciando con edema en articulaciones (limitante y deformante) con posterior iniciación de los picos febriles. También se evidenció la ausencia de un reporte de ferritina que pudiera orientar a un posible diagnóstico de $\mathrm{ES}^{27,28}$. De la misma manera, se comparó con el reporte de caso clínico de la Revista Cubana de Pediatría en el año 2012, sin embargo el abordaje diagnóstico fue más sencillo, puesto que por la clínica y los hallazgos de laboratorios e imagenológicos se pudo diagnosticar que el síndrome febril era secundario a un proceso de tuberculosis pulmonar ${ }^{28,29}$.

\section{CONCLUSIONES}

En el espectro del manejo de los casos de FOD en donde el diagnóstico definitivo muchas veces es difícil de abordar, se puede encontrar apoyo sobre algunos síntomas y hallazgos paraclínicos como los reportados en el caso clínico expuesto en este artículo, en el que ciertos síntomas poco específicos y el valor de la ferritina sérica de $1487,9 \mathrm{ng} / \mathrm{ml}$, fueron pilares para establecer el diagnostico de ES, siendo considerada la necesidad de que el paciente continuara asistiendo a consultas medicas ambulatorias con el reumatólogo pediatra para verificar la eficacia del tratamiento a base de antiinflamatorios no esteroideos y ácido acetil salicílico y la adecuada evolución de dicha enfermedad. Es importante tener claro que desde esta perspectiva existe un porcentaje creciente de pacientes en quienes es difícil encontrar una causa que explique la presencia de la FOD. Sin embargo, bajo algunas conclusiones aquí descritas, se debe reorganizar el interrogatorio y realizar una exhaustiva revisión de los resultados paraclínicos para tener por lo menos un diagnostico presuntivo o sugestivo, tal como se presentó en este artículo, en el cual juega un papel fundamental la orientación clínica asociado a un valor de ferritina elevado, dejando como conclusión de nuestro reporte la importancia de la misma para el diagnóstico de la ES.

\section{Consideraciones Éticas}

Se obtuvo consentimiento informado y se salvaguardó la identidad del paciente. Se cumplió con los principios de beneficencia y no maleficencia para el mismo. 


\section{AGRADECIMIENTOS}

Agradecemos a las instituciones donde se desarrolló el manejo de éste caso clínico y a todas las entidades que se requirieron para realizar algunos exámenes especializados. A los respectivos jurados por su valioso apoyo, aportes y orientación profesional, Doctora Ximena Monturiol y Alfredo Arenas; y de manera general a todo el núcleo familiar de los autores quienes fueron pilares indispensables para este logro.

\section{REFERENCIAS BibLIOGRÁFICAS}

1. Pinel M, Martínez M. fiebre de origen desconocido. Casos clínicos en atención primaria, Ed 26-I-07, El médico. 2007.

2. Arroyave-Hernández CM. Fiebre prolongada en enfermedades autoinmunes en pediatría. Diagnósticos y alteraciones inmunológicas. Bol Clin Hosp Infant Edo Son. 2011;28(1):23-6.

3. Alpirez-Caballero LB, Medina-Herrera EE, Fisiopatología de la fiebre. Rev Cubana Milit. 1999;28(1):49-54.

4. Peredo S, Viviani T, Peña A. Etiología del síndrome febril prolongado en niños. Rev Chi Ped. 2007;78(5):472-6.

5. Diaz J. Enfermedad de Still. Rev Med Hond. 2009;12(1):271-86.

6. Mourad O, Palda V, Detsky A. A Comprehensive evidencebased approach to fever of unknown origin. American Medical Association. Arch intern med. 2003;163:545-51.

7. Chantada G, Casak S, Daza J, Pociecha J, Bologna R. Children with Fever of Unknown Origin in Argentina: an Analysis of 113 Cases. Pediatr Infect Dis J. 1994;13(4):260-3.

8. Cunha BA. Fever of unknown origin: Clinical overview of classic and current concepts. Infect Dis Clin North Am. 2007;21(4):867-915

9. Seashore C, Lohr A. Fever of Unknown origin in children. Pediatric annals. 2011;40(1):26-30.

10. Jacobs RF, Schutze GE. Bartonella henselae as a cause of prolonged fever and fever of unknown origin in children. Clin Infect Dis. 1998;26(1):80-4.

11. Funza M. Clinical disease presentation that suggested a specific diagnosis, CID. 1998;26:80-4
12. Gonzalez S, Gomez B. Infectología clínica pediátrica. $7^{\mathrm{a}}$ edición. Mexico: McGraw-Hill Interamericana; 2003

13. Burke BA. Fever of unknown origin: focused diagnostic approach based on clinical clues from the history, physical examination, and laboratory tests. Infect Dis Clin N Am. 2007;21(4):1137-87.

14. Durack DT, Street AC. Fever of unknown origin-reexamined and redefined. Curr Clin Top Infect Dis. 1991;11:35-51.

15. Chow A, Robison JL. Fever of unknown origin in children: a systematic review. World j. pediatr. 2011;7:(1)5-10.

16. Brusch JL, Weinstein L. Fever of Unknown Origin. Med Clin North Am 1988;72:1247-61.

17. Cunha BA. Fever of unknown origin. Infect Dis Clin North Am. 1996;10(1): 111-27.

18. Cunha BA. Fever of unknown origin: clinical overview of classic and current concepts. Infect Dis Clin N Am. 2007;21(4): 867-915.

19. Petersdorf RG, Beeson PB. Fever of unexplained origin: report on 100 Cases. Medicine (Baltimore). 1961;40:1-30.

20. Lozano de León F, León Jiménez M, Gómez-Mateos JM, Corzo Delgado JE. Fiebre de origen desconocido: actitudes diagnósticas. Medicine. 1998;7:3558-66.

21. Moya Mir MS. Fiebre de Origen Desconocido. Frecuencia y Metodología Diagnóstica. Inflamación-93. 1992;279-85.

22. Bryan CS, Ahuja D. Fever of Unexplained Origin: Is There a Role for Empiric Theraphy? Infect Dis Clin N Am.2007;21(4)1213-20.

23. Greca AA. Fiebre de Origen Desconocido. Como estudiarla en 2003? Asociacion de Medicina Interna de Rosario. 2003 [publicación en línea]. Disponible en: http://www.amir.org.ar/expresidentes/pdf/Greca\%20FOD.pdf

24. De la Fuente C, Montes M. Fiebre de Origen Desconocido. En: Sociedad Española de Geriatría y Gerontología. Tratado de Geriatría para residentes. Madrid; 2007. p. 395-406.

25. Domellöf M, Dewey KG, Lönnerdal B, Cohen RJ, Hernell O. The diagnostic criteria for iron deficiency in infants should be reevaluated. J Nut. 2002;132(12):3680-6.

26. Fautrel B, Saint-Marcoux B, Taupin P, Vignes S, Rozenberg S, Koeger AC et al. Diagnostic value of ferritin and glycosylated ferritin in adult onset Still's disease. J Rheumatol. 2001;28(2):322-9.

27. Chanqueo C. Enfermedad de Still del Adulto y Valor Diagnóstico de la Ferritina Sérica. Rev. Chil. Reumatol. 2001;17(4):179-83.

28. Navalon E, Martínez E, Muñoz P. Artritis Idiopática Juvenil, variedad artritis sistémica, a propósito de un caso. Rev. bol ped. 2006;45(3):163-5

29. Vidal L, Noda A, Bouza I, Delgado M, Sánchez C, Montell O, et al. Fiebre de origen desconocido, una forma de presentarse la tuberculosis. Rev Cubana Pediatr. 2012;84(4):426-32. 